\title{
VECTOR INTERPRETATION OF STUDENTS' RESIDUAL KNOWLEDGE ASSESSMENT
}

(C) 2018

Makarov Sergey Ivanovich, doctor of pedagogical sciences, professor, head of Higher Mathematics and Economic-Mathematical Methods Department

Sevastyanova Svetlana Aleksandrovna, candidate of pedagogical sciences, associate professor of Higher Mathematics and Economic-Mathematical Methods Department Samara State University of Economics (Samara, Russian Federation)

Abstract. Residual knowledge assessment is one of the procedures used in the Russian education system to monitor the quality of education at various levels. Typically, this procedure is considered to be a computer testing of the previously learned disciplines. The analysis of test results gives grounds for making necessary decisions. This determines the importance of reliable, accessible and informative presentation of monitoring results. The paper contains a method of visualization and interpretation of residual knowledge assessment results. The authors think that it is possible to use this method for analyzing the problems of training at the individual and group levels. For statistical information processing it is offered to use a vector form of data presentation. The paper contains examples of using a vector model for estimating the level of residual knowledge in three or more disciplines. The authors propose an approach that solves the problem of test results comparability carried out in various estimation systems. The main conclusions and results can be used directly in the educational process, in the field of education management, in psychological and pedagogical work.

Keywords: mathematical methods in Pedagogy; pedagogical diagnostics; test results; control of residual knowledge; processing of monitoring data; knowledge assessment; mathematical processing of test results; visual interpretation of knowledge assessment; petal diagram.

УДК 371.3:378:811.112.2

DOI $10.24411 / 2309-4370-2018-14310$

Статья поступила в редакцию 30.09.2018

\section{ИЗ ОПЫТА ОБУЧЕНИЯ ДЕЛОВОМУ ОБЩЕНИЮ НА ИНОСТРАННОМ ЯЗЫКЕ В МАГИСТРАТУРЕ ЖЕЛЕЗНОДОРОЖНОГО ВУЗА}

(C) 2018

Одарюк Ирина Васильевна, кандидат филологических наук, доцент кафедры иностранных языков Ростовский государственный университет путей сообщения (2. Ростов-на-Дону, Российская Федерация)

Аннотация. В статье обосновывается необходимость предъявления новых требований к подготовке профессиональных кадров. Подчеркивается роль иностранных языков в процессе обучения в высших учебных заведениях, что отражено в федеральных государственных образовательных стандартах. В данном исследовании рассмотрены подходы и особенности формирования компетентностной модели обучения деловому общению на иностранном языке на примере магистратуры железнодорожного вуза. Данная модель представляется как комплекс лингвистических, коммуникативных, культурологических, психологических и профессиональных компонентов. Исследуются особенности процесса обучения иностранному языку в магистратуре технических вузов. Изучаются основания для обучения деловому иностранному языку с помощью междисциплинарного подхода. Междисциплинарный подход позволяет интегрировать знания и умения обучающихся, приобретенные ими в процессе изучения других дисциплин и успешно применяемые для освоения иностранного языка и формирования компетенции иноязычного делового общения. Представлены учебные пособия, разработанные преподавателями кафедры иностранных языков Ростовского государственного университета путей сообщения для обучающихся технических направлений подготовки магистратуры. Приведены примеры учебных заданий и некоторые технологии обучения, применяемые автором в процессе реализации рабочих программ в магистратуре железнодорожного вуза. Определены перспективные направления дальнейших исследований.

Ключевые слова: магистратура технических вузов; железнодорожный вуз; компетенция делового общения на иностранном языке; деловой немецкий язык; междисциплинарный подход; учет лингвокультурологических особенностей; учебно-методическое пособие для обучающихся магистратуры; интерактивные технологии при обучении деловому общению на иностранном языке; специальный текст; презентационная речь; симуляция.

Современные процессы всемирной глобализации и интенсификации вхождения России в мировое пространство настоятельно требуют владения иностранным языком как неотъемлемой составляющей общей профессиональной компетенции выпускников вузов. Решающее значение в этой связи имеет подготовка высококвалифицированных кадров по магистерским программам, основная цель которых заключается в формировании у обучающихся способности общения на межкультурном уровне в профессиональной сфере. Поэтому вполне обоснованной является выработка новых требований, предъявляемых к подготовке профессиональных кадров, а соответственно, и к формированию профессиональной компетентности, дающей возможность реализовать все виды деятельности (организационную, управленческую, исследовательскую) в выбранной профессии и успешное профессиональное общение на иностранном языке 
[1]. Именно целесообразностью объясняется необходимость качественного изменения и расширения содержания вузовского обучения, ориентированного на развитие познавательного потенциала и творческих способностей обучающихся, в том числе и на иностранном языке.

Естественно, что данные положения находят свое освещение в федеральных государственных образовательных стандартах (ФГОС), предназначенных обучающимся в магистратуре. Иностранный язык в деловой сфере предстает как компонент общепрофессиональной компетенции выпускников магистерских программ различных направлений подготовки в железнодорожном вузе. Так, например, во ФГОС ВО программ академической магистратуры 15.04 .04 «Автоматизация технологических процессов и производств», 08.04.01 «Строительство» указана ОПК-1 как готовность к коммуникации в устной и письменной формах на русском и иностранном языках для решения задач профессиональной деятельности. В программе 09.04.01 «Информатика и вычислительная техника» эта же мысль прослеживается в ОПК-4, где говорится, что выпускник должен владеть, по крайней мере, одним из иностранных языков на уровне социального и профессионального общения, способностью применять специальную лексику и профессиональную терминологию языка. В программе 15.04 .01 «Машиностроение» ОПК-3 определяется как способность использовать иностранный язык в профессиональной сфере.

На основании вышеперечисленных формулировок компетенций мы делаем вывод о повышении роли иностранных языков для обучающихся всех направлений подготовки вузов, в том числе и магистратуры. В основу профессиональной компетентности обучающихся магистратуры должны быть заложены коммуникативная, когнитивная, информационная, социо- и общекультурная, общая профессиональная и профессиональная компетенции студентов, которые достигаются посредством эффективного профессионального взаимодействия, в том числе и на иностранном языке. Поэтому актуальность обучения иностранным языкам, осуществляющегося на уровне, позволяющем обеспечить достижение целей межличностного и профессионального взаимодействия, не вызывает сомнения.

Проведенный нами анализ исследований и публикаций по данной тематике свидетельствует, что большинство авторов сходятся во мнении о необходимости формирования у магистрантов компетенции делового общения на иностранном языке. Основной целью процесса формирования у обучаемых вышеуказанной компетенции считается привитие им навыков и умений полноценно участвовать в международном образовательном пространстве и адекватно осуществлять межкультурную коммуникацию в соответствии со своей профессиональной и научной деятельностью. Для реализации этой цели следует активно развивать профессиональную языковую подготовку обучающихся, которая, как известно, включает теоретические знания и практические умения и навыки. Отметим также, что сама организация процесса обучения иностранному языку магистрантов непрофильных вузов, и в этом едины все ученые, настоятельно требует взаимосвязи при формировании практических навыков межкультурной коммуникации на иностранном языке с другими изучаемыми в магистратуре дисциплинами [2-6].

Как показывает практика, уровень языковой подготовки магистров в неязыковых вузах не всегда соответствует требованиям, необходимым для формирования полного объема общекультурных и профессиональных компетенций. Причины такой ситуации видятся, в первую очередь, в несовершенстве организационно-методической базы, являющейся основой процесса обучения иностранному языку в данном направлении подготовки [2]. Создавшаяся ситуация объясняется, на наш взгляд, неточной корреляцией целей обучения иностранному языку и целей высшего профессионального образования магистерской программы, недостаточным соответствием содержания дисциплины «Иностранный язык» целям и задачам, недостаточной разработанностью материалов для освоения содержания дисциплины, средств для оценивания знаний обучающихся, адекватно отражающих современную концепцию подготовки магистров. Кроме того, как отмечают Н.В. Попова, М.М. Степанова, двухлетний перерыв, образовавшийся после изучения иностранного языка по программе бакалавриата, требует восстановления приобретенных ранее умений и навыков [6].

Исходя из вышеизложенных аспектов проблемы обучения в магистратуре, связанной с необходимостью интенсификации учебного процесса, а также использования иностранного языка в профессиональной деятельности, мы определяем в качестве цели данного исследования поиск подходов и путей для формирования компетенции делового общения на иностранном языке.

Под компетенцией иноязычного делового общения мы, вслед за М.М. Степановой, понимаем «интегративное свойство личности, обеспечивающее возможность эффективного общения на иностранном языке в деловой сфере» [7]. Для реализации данной компетенции преподавателями кафедры иностранных языков Ростовского государственного университета путей сообщения разработаны рабочие учебные программы, адресованные магистрантам всех технических направлений. С целью обеспечения работы по этим рабочим планам созданы учебные пособия, в основу которых заложен междисциплинарный подход, который предполагает объединение и формирование всех составляющих процесса обучения иностранному языку магистрантов, а именно лингвистической, культурологической, психологической, профессиональной [8-10]. Мы рассматриваем данную компетенцию как комплекс определенных компонентов, которые формируются и развиваются в процессе изучения иностранного языка на всех этапах, включая магистратуру.

С целью получения основательных лингвистических знаний, умений и навыков в пособия включены разнообразные задания, направленные на усвоение специальной лексики и профессиональной термино- 
логии, особенности работы с которыми на материале текстов, связанных с железнодорожной тематикой, описаны нами ранее [11] и успешно применяются в учебном процессе. Так, например, для пополнения словарного запаса и развития мышления обучающихся служит представленная в пособии технология «Mind-Марр», освоение которой предлагается в одной из тем с помощью задания: Wie lernen Sie Ihren Wortschatz? Jedes Kapitel beinhaltet einen bestimmten Wortschatz, das heißt Wörter, die zu einem bestimmten Thema gehören. Lesen Sie den Text «Was ist MindMapping?». Machen Sie die Bekanntschaft, wie man mit Hilfe dieser Methode neue Wörter und Begriffe optimal und besser lernen kann.

Для дальнейшего развития у магистрантов языковых и речевых навыков делового общения применяются различные виды чтения, говорения и письма. В 16 темах каждого из пособий представлен материал, связанный с ситуациями делового общения в стране изучаемого языка, усвоение которого будет способствовать развитию коммуникативных навыков для решения задач профессионального межкультурного взаимодействия, научно-исследовательской деятельности, а также совершенствованию социокультурной компетенции. Так, например, к тексту «Geschäftskontakte auf einer Konferenz aufbauen» предлагается задание: Sie haben einige Einladungen zur Teilnahme an Konferenzen bekommen. Lesen Sie die aufmerksam zu, wählen Sie, an welcher Konferenz Sie teilnehmen möchten, und melden Sie sich an; к теме «Master in Deutschland. Angebot und Aufbau der Masterstudiengänge in Deutschland» дано задание: Wählen Sie das Bundesland, wo Sie den Master studieren möchten, und berichten Sie die Informationen im Kurs. Gebrauchen Sie dabei den nötigen Link. Lesen Sie den Text und besprechen Sie mit Ihrem Lernpartner Vorteile und Nachteile des Masterstudiums in Deutschland. Работая над текстом «Was ist Kommunikation?», обучающиеся знакомятся с основными моделями и принципами международной коммуникации, выполняя задание: Lesen Sie den Text und bestimmen Sie die Prinzipien der internationalen Kommunikation.

В ходе изучения делового иностранного языка особенно важным представляется преодоление барьера, связанного с разницей культур. Понимание важности этого препятствия в общении коммуникантов, принадлежащих к разным народам и странам, дает возможность избежать конфликта. Как известно, языковые ошибки в деловом межкультурном общении воспринимаются гораздо легче и бывают иногда ожидаемы, чем культурные недочеты, сделанные представителями других культур. Многие лингвисты считают эффективным систематическое, целенаправленное использование на занятиях различных ситуаций коммуникативных неудач, приводящих к непониманию и конфликтам в профессиональной сфере. Знакомство с реалиями культуры страны изучаемого языка, с разницей в менталитетах взаимодействующих сторон успешно реализуется в ходе тренировочных монологических высказываний, диалогов-обсуждений, цель которых - обучение поиску путей предотвращения и избегания конфликтов [12; 13].

Знание лингвокультурных особенностей страны изучаемого языка играет большую роль в ситуациях поиска работы, составления резюме, прохождения собеседования, делового партнерства, поэтому здесь просто необходимостью является формирование устных практических навыков обучающихся. С нашей точки зрения эффективными могут быть представленные в вышеуказанных пособиях задания следующего формата: 1) Entwickeln Sie konkrete Vorschläge für eine Corporate Identity für die unten aufgeführten neuen Unternehmen. Einigen Sie sich auf ein Unternehmen. Überlegen Sie dabei auch, wie Sie Ihre Ergebnisse präsentieren. Besprechen Sie aber auf jeden Fall an das Logo, das Unternehmensverhalten, die Unternehmenskommunikation, das Erscheinungsbild, die Berufskleidung. 2) Rekonstruieren Sie bitte das Vorstellungsgespräch zwischen dem Personalchef der Firma «Müller \& C» und dem Bewerber, Herrn Kramer.

Далее отметим, что в своей профессиональной деятельности почти все специалисты сталкиваются с иноязычной деловой документацией. Знание особенностей ведения делопроизводства на иностранном языке является необходимой частью конкурентоспособного выпускника и иноязычной компетенции магистрантов. Поэтому в процессе занятий по деловому иностранному языку магистранты РГУПС основательно изучают структуру различных видов деловых писем, клише и фразы, характерные для определенного вида писем. Для закрепления полученных знаний обучающиеся самостоятельно составляют документы для приема на работу, создают собственное резюме, пишут сопроводительные письма, переводят и ведут переписку, в том числе и электронную, ставшую в настоящее время, по мнению А.О. Стеблецовой, воплощением «письменной деловой документации, делового дискурса и национальной деловой культуры» с предполагаемыми деловыми партнерами [14]. Приведем в качестве образца следующее задание из пособия: Sie sind Mitarbeiter(in) von der Firma Müller \& Söhne, schicken Sie eine E-Mail mit dem Vertragsentwurf an die Partnerfirma, die die Mitarbeiter der Partnerfirma weiter bearbeiten sollen.

Не менее важной частью в структуре компетенции иноязычного делового общения является психологическая составляющая, которая, на наш взгляд, объединяет все составляющие и обеспечивает решение практических коммуникативных задач с помощью знаний, умений, навыков в области психологии. В этом ракурсе следует говорить об особенностях реализации функции убеждения в иноязычной деловой коммуникации. Поскольку в современном деловом мире информирование партнеров не является основополагающим моментом, то во главу угла ставится речевое воздействие на партнера по общению с целью реализации прямых или скрытых намерений, заключающихся в достижении целей, выгодных для компании, положительное решение собственных задач и склонение делового партнера к нужному решению. В этом проявляется языковая функция воздействия, которая реализуется с помощью определен- 
ных вербальных способов. Как считают ученые, в задачи общающихся входит незаметно, тонко, осторожно оказывать воздействие на собеседников, стремясь при этом изменить мнение партнеров по общению в нужном направлении [15]. Здесь, с нашей точки зрения, целесообразно применение определенных способов влияния и манипуляций психологии делового общения, а также прагмалингвистических стратегий скрытого речевого воздействия.

По утверждению ученых, занимающихся исследованием прагмалингвистического аспекта речевого общения, следует говорить также о скрытом воздействии, особенностью которого является неосознанность и машинальность его реализации, одновременность использования говорящим средств прямого и непрямого воздействия для актуализации своих скрытых интенций. Актуализация скрытого воздействия предполагает выбор говорящим заавтоматизированных, находящихся в его подсознании лингвистических единиц. Процесс актуализации такого воздействия делает возможным изменение отношения деловых коммуникантов к обсуждаемой информации, что может вызвать также и изменение их поведения по отношению к речевому событию [16]. В качестве средств скрытого речевого воздействия используются различные лингвистические единицы (слова, словосочетания, речевые стереотипы). Так, например, при подготовке презентаций на немецком языке активизация внимания слушателя достигается: 1) выделением структуры выступления (- zuerst ..., von Anfang an ..., weiter ..., zum Schluss muss man sagen, dass ...; - Was ich noch sagen wollte: ...; - Nach dem Gesagten möchte ich folgendes sagen (betonen, unterstreichen) ...); 2) диалогизацией монолога с помощью вопросов самому себе (- Es ist wichtig zu wissen, dass ...; - Ich vertrete den Standpunkt, daß ...; - Mir scheint, dass ...); 3) затягиванием сообщения важной информации, наверняка заинтересующей слушателей (- Davon werde ich weiter sprechen ...;-Davon ist die Rede später ...); 4) акцентировкой важной информации (- Besonders wird darauf hingewiesen, dass ...; Es muß betont werden, dass ...) [17].

К эффективным методам обучения умению убеждать в ситуациях деловой коммуникации на иностранном языке относят традиционно деловые игры, активизирующие учебный процесс, приближающие его к реальным условиям профессиональной действительности [18]. Поэтому в разработанных нами учебных пособиях использованы задания следующего плана: Stellen Sie das Unternehmen vor, in dem Sie arbeiten oder das Sie gut kennen. Beachten Sie folgende Punkte: Größe, Mitarbeiterzahl, Standort, Gründung, Industrie, Handel oder Dienstleistung, Export, Kunden.

Кроме того, обучающимся предложены коммуникативные задания на основе методики симуляции. Как интерактивная технология обучения симуляция представляет собой некую безопасную среду, в которой ее участники стараются справиться с поставленной перед ними проблемой, преодолеть возникающие коммуникативные неудачи в смоделированных ситуациях профессионально ориентированного об- щения. Следует отметить здесь, что при реализации симуляции нельзя говорить об эффективности либо неэффективности общения, ведь главной целью данной технологии считается овладение соответствующим коммуникативным опытом, с помощью которого станет возможным разрешение подобных затруднений в будущем. В этом заключается компенсаторная функция симуляции [19]. В качестве подобного задания мы используем разработанный референтом Гете-Института А. Засс проект «Немецкий язык для профессии с помощью учебно-тренировочной фирмы» и предлагаем обучающимся задание: «Planen und präsentieren Sie eine eigene Firma».

В задачи развития и совершенствования коммуникативной компетенции магистров технических направлений входит также овладение навыками публичного выступления и основами представления_результатов проведенных исследований в соответствии с коммуникативными стратегиями и тактиками научной речи и с учетом особенностей международной коммуникации. Часто встречающимися в учебной деятельности ситуациями деловой речи стали конференции, собрания, переговоры, публичные выступления на мероприятиях и служащие для их более удачной интерпретации презентации. Для этого предлагаются, например, такие виды учебных заданий, как доклады на иностранном языке, подготовка рефератов, проектных заданий, курсовых и дипломных работ. С целью успешного овладения навыками презентирования определенной информации на занятиях в магистратуре следует рассматривать особенности создания публичной речи как литературного жанра, включающего логическую структуру: проблема $\rightarrow$ тема $\rightarrow$ тезис $\rightarrow$ аргумент. Выступление предполагает наличие некоторых предлагаемых слушателям рекомендаций, формулировка которых предстает в емкой, запоминающейся языковой форме. Композиционное строение выступления основывается на принципах (краткости, последовательности, целенаправленности, усиления и результативности). Структура публичной речи представляет собой обычно традиционную трехсоставную композицию: вступление, основная часть, заключение. Чтобы аудитория стала не пассивным, а активным участником презентационного выступления и воспринимала предмет речи в соответствии с намерениями говорящего, структуру выступления следует делать четкой и понятной для слушателя [17].

И наконец, профессиональный компонент компетенции делового общения представляет знания, умения навыки, формирующиеся у магистров в процессе изучения специальности. Поскольку структура и содержание всего объема знаний связано со специализацией обучающихся, то эта составляющая компетентностной модели определяется как вариативная. На этом этапе междисциплинарный подход к процессу обучения обеспечивает удачное сочетание знаний по специальности и знаний языка и способствует включению профессиональных компетенций в компетенцию иноязычного делового общения. Неотъем- 
лемой частью профессиональной компетентности магистров в техническом вузе является умение делать корректный перевод специальных текстов [2022]. Поэтому, в первую очередь, в созданных преподавателями кафедры пособиях представлены задания по изучающему чтению, предполагающему адекватный перевод научно-технических текстов. Наряду с такого рода заданиями в пособия включены и другие виды заданий, заключающиеся в выборочном и реферативном переводе, составлении аннотаций, глоссариев к текстам по специальности, поисковых видах чтения. Например: 1) Machen Sie sich mit nützlichen Formulierungen bei der Vorstellung der Ergebnisse der Forschungsarbeit bekannt und gebrauchen Sie sie bei der Vorstellung Ihrer eigenen wissenschaftlichen Arbeit. 2) Lesen und übersetzen Sie den Text mit Hilfe des Wörterbuches. Definieren Sie das Genre des gelesenen Textes (Artikel, Anleitung, Werbung, Referat).

Процесс обучения по магистерским программам предъявляет новые, более высокие требования к формированию такого вида деятельности, как аудирование. Восприятие на слух является сложным процессом, включающим перцептивную и мыслительномнемическую деятельности, важной составляющей которых является смысловое прогнозирование содержания общения. В задачи преподавателя входит формирование основ для правильного понимания, переработки и реакции на получаемую информацию, умение правильно представить ее в соответствующих ситуациях делового общения. В нашей практике мы считаем приемлемым обучение аудированию на каждом занятии, при работе над каждым заданием. В то же время в нами разработаны специальные задания по обучению аудированию в соответствии с методикой, описанной О.А. Малетиной [23]. Аудиторная работа подразделяется на три основных этапа и включает задания, подлежащие выполнению до представления текста, при его прослушивании, а также после восприятия его обучающимися. Отметим, что задания, предлагаемые обучающимся после прослушивания аудиотекста, имеют творческий, интерактивный характер: например, обсудить предложенную тему, презентовать ее, найти дополнительную информацию в интернете, предложить выход из сложной ситуации и т.д.

Данные учебные пособия, размещенные в электронном каталоге библиотеки вуза, довольно успешно проходят апробацию и используются нами как для аудиторной, так и для самостоятельной работы с обучающимися.

Резюмируя вышесказанное, отметим, что в соответствии с новой целью обучения иностранному языку в магистратуре технического вуза предполагается профессионально-компетентностная подготовка обучающихся. В ее основе находится междисциплинарный подход, который включает в себя комплекс знаний и умений, полученных в процессе изучения дисциплин профессионального, общенаучного, гуманитарного блоков. Для реализации профессионально-компетентностной подготовки через овладе- ние иностранным языком необходима профессионально- и научно-ориентированная система организационно-методического обеспечения (рабочие программы, учебные пособия), разработка которого непременно должна осуществляться с учетом всех аспектов процесса обучения иностранному языку. На основе данных положений преподавателями кафедры иностранных языков РГУПС были разработаны рабочие учебные программы по направлениям подготовки магистратуры. В соответствии с программами созданы учебные пособия, в содержание которых включены задания, связанные с выявлением проблем и поиском возможных вариантов их решения, с функционалом и отношениями в сфере профессиональной и научной деятельности. Необходимым условием для успешной работы по овладению иноязычной деловой коммуникацией является применение интерактивных методов и технологий обучения в сотрудничестве обучающего и обучаемого. Перспективой для дальнейших исследований в данном направлении нам видится поиск новых, более эффективных способов обучения, разработка новых заданий, отвечающих современным требованиям к качеству подготовки выпускников.

\section{Список литературы:}

1. Чашко М.М. Особенности обучения иностранным языкам на уровне магистратуры // Вестник Московского государственного лингвистического университета. Образование и педагогические науки. 2018. № 790. C. 104-113.

2. Ширяева Н.Н. Организационно-методическое обеспечение обучения иностранному языку студентов магистратуры: автореф. дис. ... канд. пед. наук. Нижний Новгород, 2013. 19 с.

3. Ямшанова В.А., Кручинина А.А., Тумарова Т.Г. Иностранный язык в магистратуре: опыт первого года // Известия Санкт-Петербургского университета экономики и финансов. 2010. № 1. С. 135-142.

4. Малетина О.А. Специфика обучения иностранному языку магистрантов // Вестник Волгоградского государственного университета. Серия 6: Университетское образование. 2014. № 1 (15) С. 38-42.

5. Степанова М.М. Современные подходы к обучению иностранному языку в магистратуре неязыкового вуза // Научно-технические ведомости СанктПетербургского государственного политехнического университета. Гуманитарные и общественные науки. 2010. № 2 (111). C. 109-114.

6. Попова Н.В., Степанова М.М. Междисциплинарный подход к преподаванию иностранного языка в непрофильной магистратуре // Актуальные проблемы науки и образования: мат-лы второй междунар. науч. конф. Ставрополь: СевКавГТУ, 2010. C. $76-81$.

7. Степанова М.М., Х Хайкин В.Д. Аксиологический подход к формированию компетенции иноязычного делового общения в нелингвистическом вузе // Молодой ученый. 2012. № 12. С. 512-514.

8. Одарюк И.В. Иностранный язык (немецкий) для решения задач профессиональной деятельности: 
учебно-методическое пособие для обучающихся магистратуры и аспирантуры. Ростов-на-Дону: ФГБОУ ВО РГУПС, 2017. 78 с.

9. Одарюк И.В. Иностранный язык как средство делового общения (немецкий язык): учебно-методическое пособие для обучающихся магистратуры. Ростов-на-Дону: ФГБОУ ВО РГУПС, 2017. 93 с.

10. Пернаки Е.Н. Формирование компетенции обучающихся в области деловой коммуникации: учебно-методическое пособие по немецкому языку. Ростов-на-Дону: ФГБОУ ВО РГУПС, 2018. 137 с.

11. Одарюк И.В. Специфика перевода терминов в специальных текстах (на материале текстов железнодорожной направленности) // Филологические науки. Вопросы теории и практики. 2016. № 12 (66). В 4 ч. Ч. 2. С. 141-143.

12. Одарюк И.В. Лингвокультурологические особенности и их роль в успешности бизнес-коммуникации // Вопросы социально-гуманитарных наук. Научно-практический журнал. 2006. № 2 (7-8). C. $48-51$.

13. Касаткина Т.Ю. Специфика организации обучения иностранному языку в нелингвистической магистратуре // Вестник Волгоградского государственного университета. Серия 6: Университетское образование. 2014. № 1. С. 38-42.

14. Стеблецова А.О. Электронное письмо в современной деловой культуре // Вестник Воронежского государственного университета. Серия: Филология. Журналистика. 2010. № 1. С. 99-102.

15. Тер-Минасова С.Г. Война и мир языков и культур. М.: Слово, 2008. 334 с.

16. Матвеева Г.Г. Скрытые грамматические значения и идентификация социального лица (портрета) говорящего: дис. ... д-ра филол. наук. СПб., 1993. 449 c.

\section{TEACHING BUSINESS \\ FOREIGN LANGUAGE COMMUNICATION IN MASTER'S COURSES AT RAILWAY TRANSPORT UNIVERSITY}

(C) 2018
17. Одарюк И.В., Войкина А.Ю. Презентационная речь как технология формирования компетенции делового общения на иностранном языке // Преподаватель высшей школы в XXI веке: тр. междунар. науч.практ. интернет-конф. / отв. ред. И.В. Одарюк, Т.Е. Исаева. Ростов-на-Дону: РГУПС, 2014. С. 204-209.

18. Доможирова М.А. Деловая игра в обучении профессионально-ориентированному общению на иностранном языке студентов неязыковых вузов: автореф. дис. ... канд. пед. наук: 13.00.08. СПб., 2002. $17 \mathrm{c.}$

19. Одарюк И.В., Колмакова В.В. Симуляция как интерактивная технология при обучении деловому общению на иностранном языке // Филологические науки. Вопросы теории и практики. 2016. № 5-2 (59). C. 201-203.

20. Аносова Н.Э. Переводческая компетентность магистров в техническом вузе // Научно-технические ведомости Санкт-Петербургского государственного политехнического университета. Гуманитарные и общественные науки. 2010. № 2 (111). С. 88-92.

21. Lazarou E., Odarjuk I.V. Der Fachtext als Hauptbasis im fachsprachlichen Deutschunterricht // Преподаватель высшей школы в XXI веке: труды междунар. науч.-практ. интернет-конф. Ростов-наДону: РГУПС, 2017. С. 30-44.

22. Степанова М.М. Формирование компетенции делового общения на иностранном языке в магистратуре технического вуза // Научно-технические ведомости Санкт-Петербургского государственного политехнического университета. Гуманитарные и общественные науки. 2013. № 2 (172). С. 108-112.

23. Малетина О.А. Методические рекомендации по формированию аудитивных навыков в неязыковом вузе // Lingua mobilis. 2010. Т. 23, № 4. C. 114119.

\author{
Odaryuk Irina Vasilievna, candidate of philological sciences, \\ associate professor of Foreign Languages Department \\ Rostov State Transport University (Rostov-on-Don, Russian Federation)
}

Abstract. The paper explains the necessity of new professional training requirements. The role of foreign languages at higher educational institutions is emphasized, which is reflected in the Federal National education standards. The paper dwells upon approaches and peculiarities of developing a competence-based model of teaching business foreign language communication to postgraduate students of the railway transport university. The paper gives examples of tasks and teaching technologies, used by the author in the process of implementing the teaching programmes for postgraduate students of the railway transport university. The above-mentioned model is viewed as a complex of linguistic, communicative, culturological, psychological and professional components. The characteristic features of teaching a foreign language to postgraduate students of technical universities are researched. The grounds for using an interdisciplinary approach in teaching a foreign language for business communication are considered. The interdisciplinary approach allows to integrate students' knowledge and skills acquired in the process of studying other subjects and to successfully implement them in mastering a foreign language and developing a competence in business foreign language communication. The paper gives an overview of the study guides developed by teachers of Foreign Languages Department of the Rostov State Transport University for postgraduate students majoring in technical subjects. The perspectives of further research are defined.

Keywords: postgraduate course at technical higher educational institution; railways transport university; competence of business foreign language communication; business German; interdisciplinary approach; lingvocultural features; an educational and methodical manual for postgraduate students; interactive technologies in teaching business foreign language communication; special text; presentation speech; simulation. 